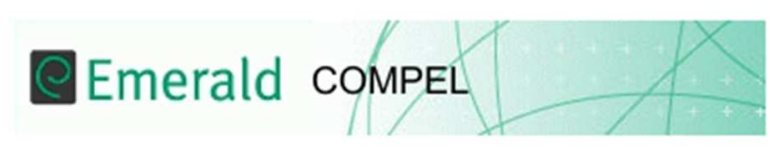

\title{
Analysis of the stator topology impact on cogging torque for surface permanent magnet motor
}

\begin{tabular}{|r|l|}
\hline Journal: & $\begin{array}{l}\text { COMPEL: The International Journal for Computation and Mathematics in } \\
\text { Electrical and Electronic Engineering }\end{array}$ \\
\hline Manuscript ID: & COMPEL-08-2014-0213 \\
\hline Manuscript Type: & Original Article \\
\hline Keywords: & $\begin{array}{l}\text { Surface permanent magnet (SPM) motor, Cogging torque, Finite element } \\
\text { analysis (FEA), Slot skewing, Soft magnetic composite (SMC), Stator } \\
\text { topology }\end{array}$ \\
\hline \multicolumn{2}{|l}{} \\
\hline
\end{tabular}

SCHOLARONE ${ }^{\mathrm{m}}$

Manuscripts 


\title{
Analysis of the stator topology impact on cogging torque for surface permanent magnet motor
}

\begin{abstract}
Purpose - The paper investigates the impact of the stator core design for a surface permanent magnet (SPM) motor on the cogging torque profile. The objective is to show how the cogging torque of this type of motor can be significantly reduced by implementing an original compound technique by skewing stator slots and inserting wedges in the slot openings.
\end{abstract}

Design/methodology/approach - At the beginning generic model of a SPMM is studied. By using FEA, for this idealised assembly, characteristics of cogging and electromagnetic torque are simulated and determined for one period of their change. Afterwards, actual stator design of the original SPMM is described. It is thoroughly investigated and the torque characteristics are compared with the generic ones. While the static torque is slightly decreased, the peak cogging torque is almost doubled and the curve exhibits an uneven profile. The first method for cogging torque reduction is skewing the stator stack. The second technique is to insert wedges of SMC in the slot openings. By using $2 \mathrm{D}$ and 2 1/2D numerical experiment cogging curves are calculated and compared. The best results are achieved by combining the two techniques. The comparative analyses of the motor models show the advantages of the proposed novel stator topology.

Findings - It is presented how the peak cogging torque can be substantially decreased due to changes in the stator topology. The constraint is to keep the same stator lamination. By skewing stator stack for one slot pitch 10 deg. the peak cogging torque is 3 fold reduced. The SMC wedges in slot opening decrease the peak cogging almost 4 times. The novel stator topology, a combination of the former ones, leads to peak cogging of respectable $0.182 \mathrm{Nm}$, which is reduced for 7.45 times.

Originality/value - The paper presents an original compound technique for cogging torque reduction, by combining the stator stack skewing and inserting SMC wedges in the slot openings.

Keywords - Surface permanent magnet (SPM) motor, Cogging torque, Finite element analysis (FEA), Slot skewing, Soft magnetic composite (SMC), Stator topology.

Paper type - Research paper

\section{Introduction}

High-performance drives with Permanent Magnet Motors (PMMs) require motors that produce smooth static torque with rather low component of cogging torque. However, in many commercially available drives, the typical value of cogging torque is $5-15 \%$ of the rated load torque. Moreover, due to the imperfect manufacture and mass production, even properly designed PMMs may have higher cogging torque, as much as more than $25 \%$ of the rated torque (Gasparin and Fiser, 2013). Hence, to produce permanent magnet motors that meet prescribed requirements of low torque ripple, accurate methods for torques prediction and assessment are necessary in early designing phase (Ionel et al. , 2005; Petkovska and Cvetkovski, 2011). In surface permanent magnet (SPM) motors, the cogging torque is caused by the interaction between the PM field and the variable stator reluctance due to slotting. To smooth out the cogging peaks, it is required to optimize this interaction. In the last decades, the problem has been identified and widely studied (Gonzales et al., 2007; Zhu et al., 2008;). It has been applied a variety of techniques and methods to reduce a detrimental effect of cogging torque in PM motors (Bianchini et al., 2012; Hanselman, 1994; Levin et al., 2013).

Generally, these methods fall into two categories: drive strategies and geometric design of the PMMs (Kudrjavtsev and Kilk, 2014). The first approach, indeed not considered in this paper, includes selection of the proper current waveforms, control strategy of the drive, switch-on/off techniques, duty cycle, etc. The second approach is more common and more general. It deals with design considerations of the stator (Choi et al., 2011; Guemes et al., 2011; Kwack et al., 2010) and rotor lamination, the air-gap length and profile (Gholamian and Rashidaee, 2012), as well as the permanent magnets shaping (Petkovska et al., 2013). In the literature are presented various techniques for cogging torque reduction: stator slot skewing or permanent magnet skewing (Fei and Zhu, 2013), inserting flux barriers (Stumberger et al., 2008), shaping and tapering the permanent magnet poles (Chen et al., 2010; Kim et al., 2003), designing air-gap profile, etc.

In the present paper the focus is put on the influence of stator topology and design on the cogging torque peak value and a profile. First, an investigative study of stator lamination cut on the level of cogging torque (Petkovska and Cvetkovski 2012) is presented. The numerical FEA tool is used for calculations of the cogging waveforms. The mitigation of the number of ripples and reduction of the peak cogging torque is achieved through implementation of two techniques: skewing the stator slots and inserting the wedges of Soft Magnetic Composite (SMC) in the slot openings. The anticipated constraints are to keep the same cut of the stator lamination and the material properties (stator and rotor iron cores, as well as permanent magnets type). On the basis of the analysed results, a compound solution for substantial reduction of the peak cogging torque, without deterioration the performance characteristics of a permanent magnet motor, is proposed. 


\section{Problem definition}

The analysis model is a surface permanent magnet motor (SPMM) with 18 A rated current, $0-10 \mathrm{Nm}$ torque control, and 0-4000 rpm speed control. There are 6 surface mounted high energy Sm-Co magnet poles on the rotor that are magnetised in radial direction. The stator lamination is with 36 slots, where 3 single-layer stage windings are placed. The drive is connected to a current-source inverter and is controlled by rectangular current waveforms. At each instant of time one winding is energised by a positive current wave $+\mathrm{I}$, the other by negative $-\mathrm{I}$, while the third winding remains unexcited (Petkovska and Cvetkovski, 2011).

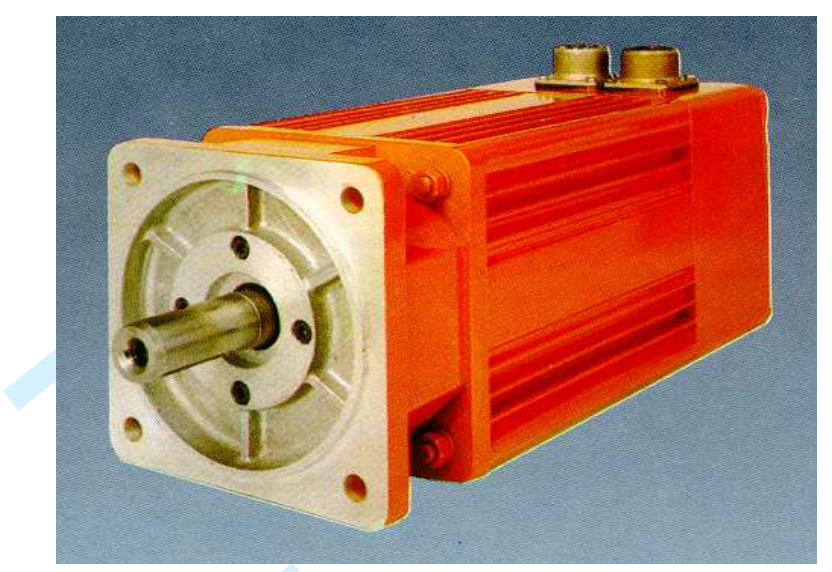

Figure 1. Outer view of the surface permanent magnet motor

\subsection{Generic model}

The initial geometry of the studied prototype motor-generic SPMM is shown in Figure 2. In this design the stator lamination on the outer surface is manufactured as smooth cylinder without punches and cuts. To reduce the rotor inertia and improve the control response of the motor, an important part of rotor core, with respect to the number of magnets, has been removed.

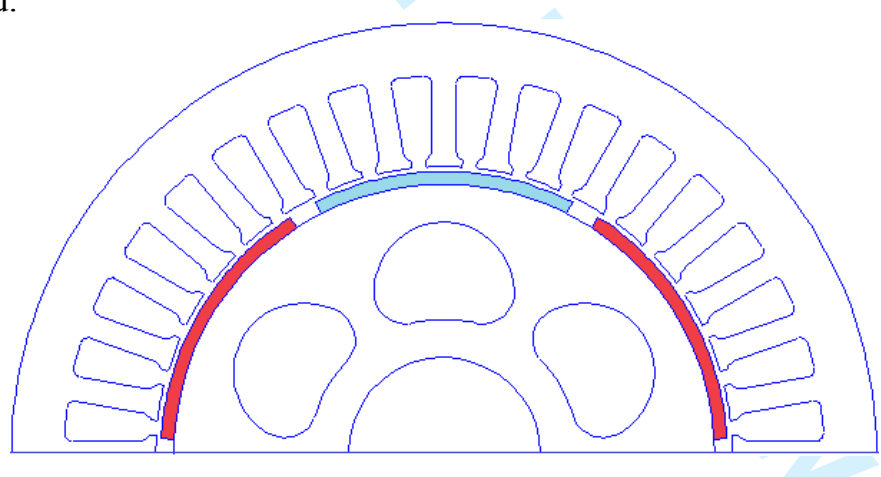

Figure 2. Cross section of the generic SPMM

For prediction torque characteristics of the generic SPMM the two-dimensional Finite Element Analysis (FEA) is employed. The weighted stress tensor volume integral is used to calculate torques. This approach greatly simplifies the computation of torques and gives the most accurate results, as compared to line integration to calculate Maxwell stress tensor or application of energy concept and numerical differentiation of the air-gap coenergy. The finite element mesh is generated with 103,532 nodes and 206,043 elements. In order to achieve closer estimation of torques, the mesh density in the air gap, where the Maxwell stress is the highest, is particularly refined. The calculations start at no-load, i.e. without current in stator windings, when the magnetic field is induced only by the permanent magnets. The rotor is displacing for $1^{0}$ mech. in clockwise direction and the cogging torque is calculated. In Figure 3 is depicted the cogging torque profile $T_{\operatorname{cog}}=f(\theta)$ for the generic SPMM. 


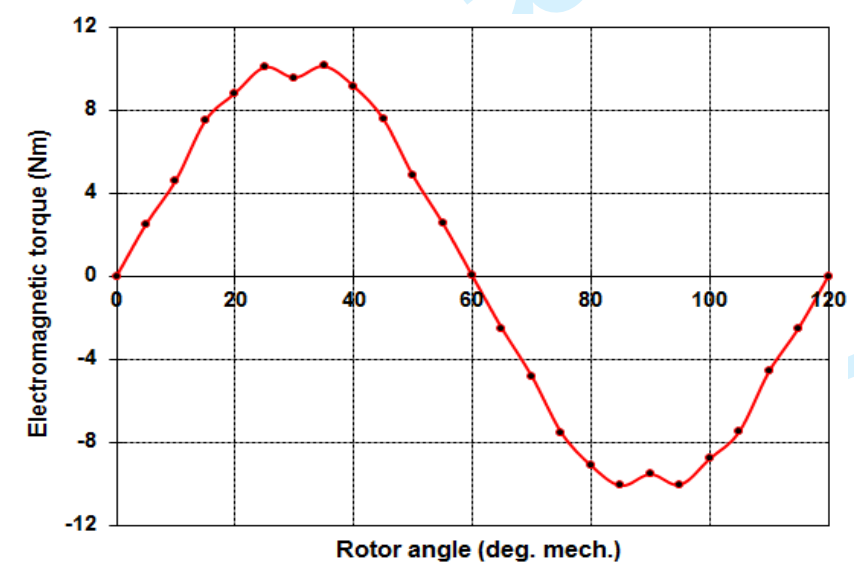

Figure 4. Static torque characteristic on full load

From the above figures, one can observe the full symmetry of the both characteristics. In the generic model of analysed surface permanent magnet motor, the peak value of the cogging torque is $0.743 \mathrm{Nm}$, which is $7.35 \%$ from the peak static torque $10.1 \mathrm{Nm}$.

\subsection{Original SPM Motor}

The analysed generic SPMM model is simplified as ideal assembly with perfect manufacture and has no cuts, notches and interlocks. However, these conditions are unlikely to be achieved in practice. For example, the stator outer surface is never perfectly circular, since it usually has flat surfaces which are narrower than the stator outer diameter, and are often employed to reduce the volume of stator core. 
From the other side, there exist notches, slots and cuts for keeping the laminations to the frame firmly, as well as interlocks to align the magnetic sheets. All they have different shapes and, in general, an asymmetrical distribution. Thus, these stator asymmetries which really exist in every motor design, will cause the magnetic field distribution in the stator core to digress significantly from that predicted for the idealised generic model, and may introduce high localised magnetic saturations. As a result, the peak value of the cogging torque may be increased significantly. Even more, both the profile and the periodicity of the cogging torque may exhibit rather uneven. This is thoroughly studied and reported in the present paper.

The half cross section of the actual design of the analysed motor is presented in Figure 5. This motor model is original SPMM, seen in Figure 1, and is taken from a production line. Main dimensions are the same as in generic SPMM, but the stator core outer surface is substantially changed.

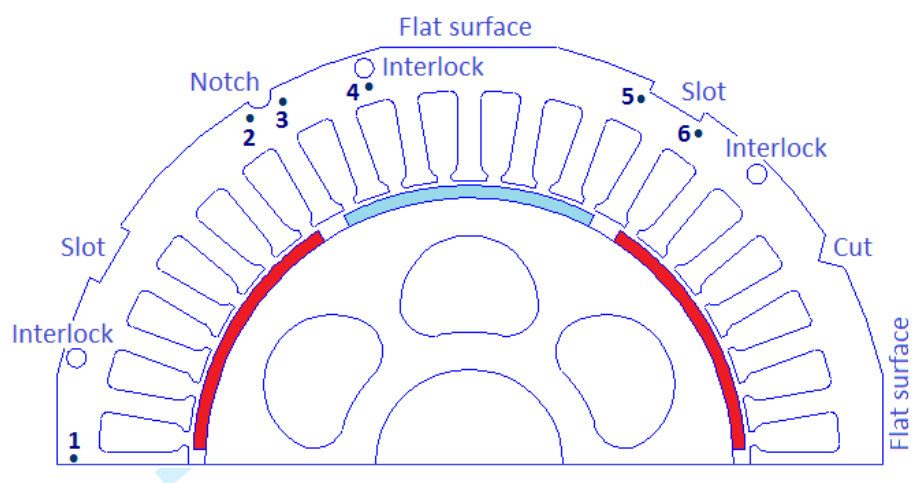

Figure 5. Half cross section of the original SPMM

There are four flat edges and four symmetrically distributed slots with rectangular shape. Also there exist a pair of circular notches and a pair of triangular cuts, standing diametrically opposite and perpendicularly each to other. In addition six circular interlocks are symmetrically punched. In the figure are depicted 6 typical points, where the higher saturation is anticipated to appear. The more important stator and rotor design parameters of the original SPMM are listed in Table 1.

Table 1 Design parameters of the motor topology - original SPMM

\begin{tabular}{|l|l|l|l|}
\hline Stator outer radius & $67.5 \mathrm{~mm}$ & Stator stack length & $90 \mathrm{~mm}$ \\
\hline Stator bore radius & $45.0 \mathrm{~mm}$ & Stator slot height & $13.3 \mathrm{~mm}$ \\
\hline Rotor outer radius & $44.2 \mathrm{~mm}$ & Mid-tooth width & $3.83 \mathrm{~mm}$ \\
\hline Rotor shaft radius & $15.0 \mathrm{~mm}$ & Tooth tip height & $0.95 \mathrm{~mm}$ \\
\hline Air-gap length & $0.8 \mathrm{~mm}$ & Flat edge length & $28.3 \mathrm{~mm}$ \\
\hline Permanent magnet height & $2.0 \mathrm{~mm}$ & Notch radius & $2.0 \mathrm{~mm}$ \\
\hline PM residual inductance $\mathrm{B}_{\mathrm{r}}$ & $1.176 \mathrm{~T}$ & Interlock radius & $1.5 \mathrm{~mm}$ \\
\hline PM relative recoil permeability $\mu_{\mathrm{r}}$ & 1.05 & Rectangular slot: width $\times$ depth & $9.5 \mathrm{~mm} \times 1.8 \mathrm{~mm}$ \\
\hline
\end{tabular}

The impact of the stator asymmetry on performance of the original SPMM is studied by employing FEA. The results are presented in figures and charts. In Figure 6 the open-circuit field contours and flux density distribution at $0^{0}$ rotor position, for the generic SPMM (a), and original SPMM (b) are presented. Using the same legend for the flux density, the above figures illustrate the influence of the stator asymmetries. As it was anticipated, there is evident an important localised field saturation in the distinctive points. For the initial position of the rotor $\theta=0^{0}$ is selected to be the aligned position of the rotor field (N-pole of permanent magnets) and the resultants stator field (S-pole of the windings). To complete magnetic field analysis of SPM motor, the magnetic flux density in the selected points of the stator back iron (as shown in Figure 5) is determined. 


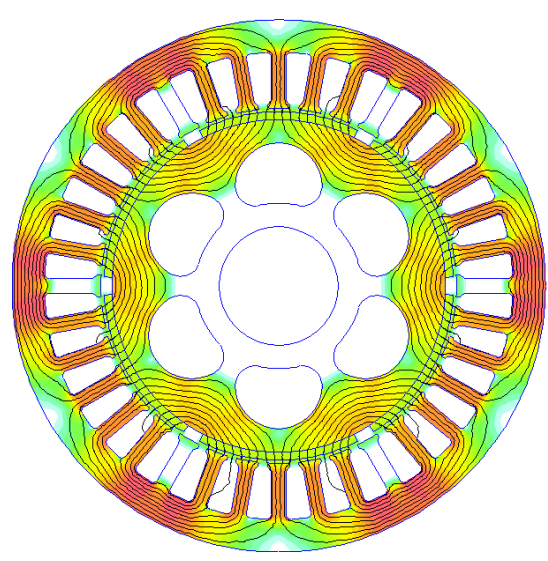

(a) Generic SPMM
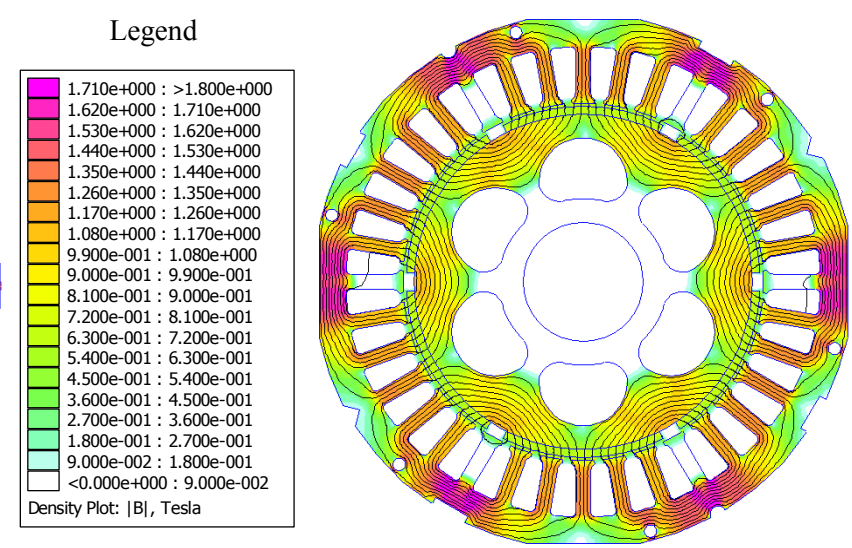

(b) Original SPMM

Figure 6. Magnetic field induced by PM: flux lines and flux density distribution at $0^{0}$ rotor position

A particular emphasis is put on the cogging torque analysis, both the peak value and the profile. The magnetic field is excited by PM only, while the rotor is displaced for $1^{0}$ mech. step, along one pole pitch $60^{\circ}$ mech. in the clockwise direction. A numerical experiment and FEM validation for the original SPMM is used. Cogging torque is computed by means of consecutive magnetostatic simulations at different rotor positions. From the set of calculations, the cogging torque characteristic, spanned to one whole period of change, is obtained. In Figure 7 is presented the full cycle of the cogging torque profile for the original SPMM, in comparison with the previously obtained cogging torque of the generic one. Obviously, the unavoidable interventions on the outer stator surface resulted in peculiar and asymmetric cogging torque profile, at significantly increased peak value to $1.356 \mathrm{Nm}$, which is 1.825 times higher than in the generic model. Simultaneously, the periodicity of the cogging torque profile from one slot pitch $\left(10^{\circ}\right.$ mech. $)$ in the generic model has been increased to one pole pitch $\left(60^{0}\right.$ mech. $)$ in the original model. Along the period, one point of mirrored symmetry is at $15^{\circ}$, while another is moved for half a period and is placed at $45^{\circ}$. These points are definitely dependent on the shaping the outer stator surface, by cutting flats and inserting notches and interlocks.

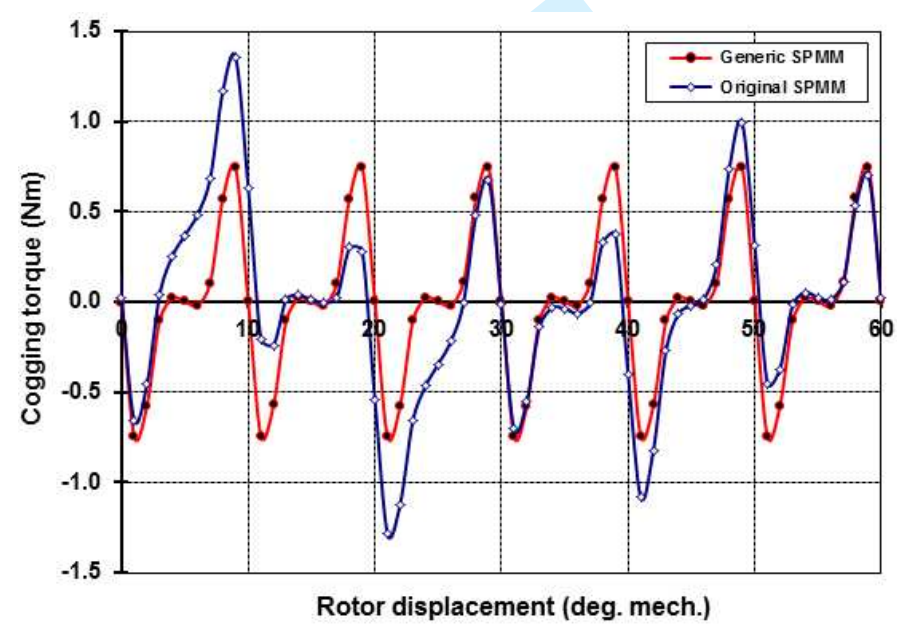

Figure 7. Cogging torque profile for generic and original SPMM

For the static torque characteristic of the original SPM motor to be predicted, field computations continue at rated load operation. Staring with the same initial position as before, rotor is displaced for $5^{0}$ in clockwise direction. Comparison of the characteristics on full load in the generic and original SPMM for a pair of pole pitch is given in Figure 8, and no significant impairment is observed. 


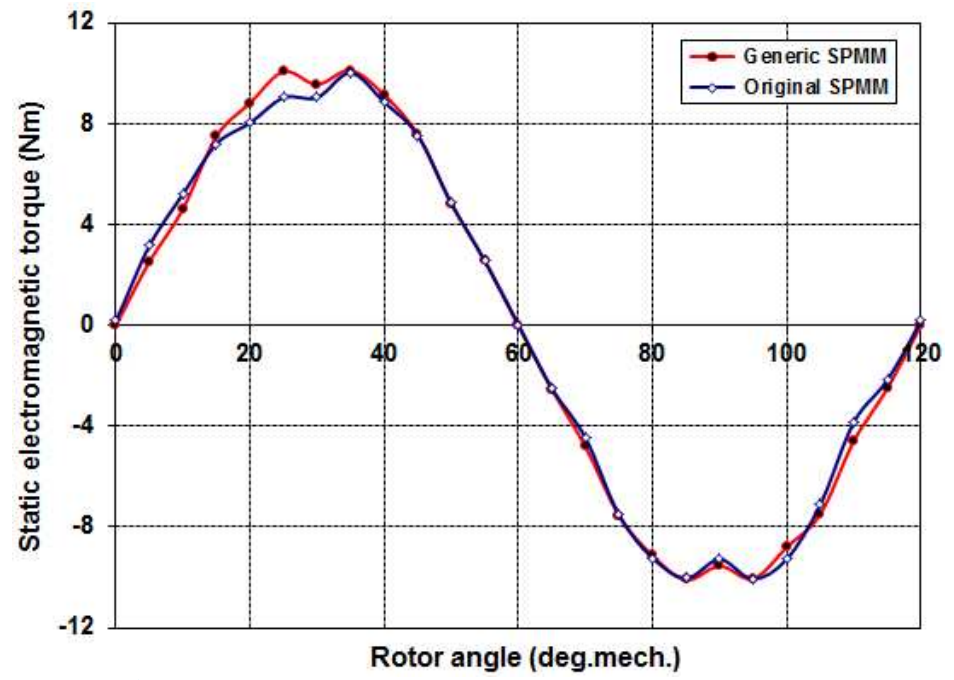

Figure 8. Comparison of static electromagnetic torque characteristics on full load

The static torque peak value of the original SPMM in Figure 8 is $10.0 \mathrm{Nm}$. Thus, in the original motor, relative value of the cogging torque becomes $13.56 \%$, giving almost doubled rise to the respective value of the generic motor. Consequently, in the design topology of the original SPM motor, additional actions should be done, in order to mitigate the effect of the stator asymmetries on the peak cogging torque level, as well as to reduce the number of ripples per period of its change.

\section{Problem Solution}

Cogging torque $T_{c o g}$ is probably the most annoying parasitic element in PM motor design because it is an undesired motor output. It is produced due to the interaction between the rotor magnets and the slots and poles of the stator, i.e. the stator saliency, and is given by (Hanselman, 1994):

$$
T_{\operatorname{cog}}=-\frac{1}{2} \phi_{g}^{2} \frac{d R}{d \theta}
$$

where $\phi_{\mathrm{g}}$ is the air gap flux, $R$ is the air gap reluctance and $\theta$ is the angle of rotor displacement.

Obviously, to reduce $T_{\operatorname{cog}}$ it is required to reduce any or both terms of equation (2). However, before considering a specific cogging torque reduction technique, it is important to note that $\phi_{\mathrm{g}}$ cannot be significantly reduced since it also produces the motor back EMF and the desired electromagnetic torque. More importantly, most techniques employed to reduce cogging torque also reduce and resulting static torque.

Cogging torque in permanent magnet motors is a dominant factor that influences the torque ripple level and the control precision. Hence, techniques to reduce the peak cogging torque play a prominent role in the motor design and a challenge for motor designers. Numerous methods and techniques have been introduced. To avoid long descriptions, an outline of the most common techniques is sketched in Figure 9.

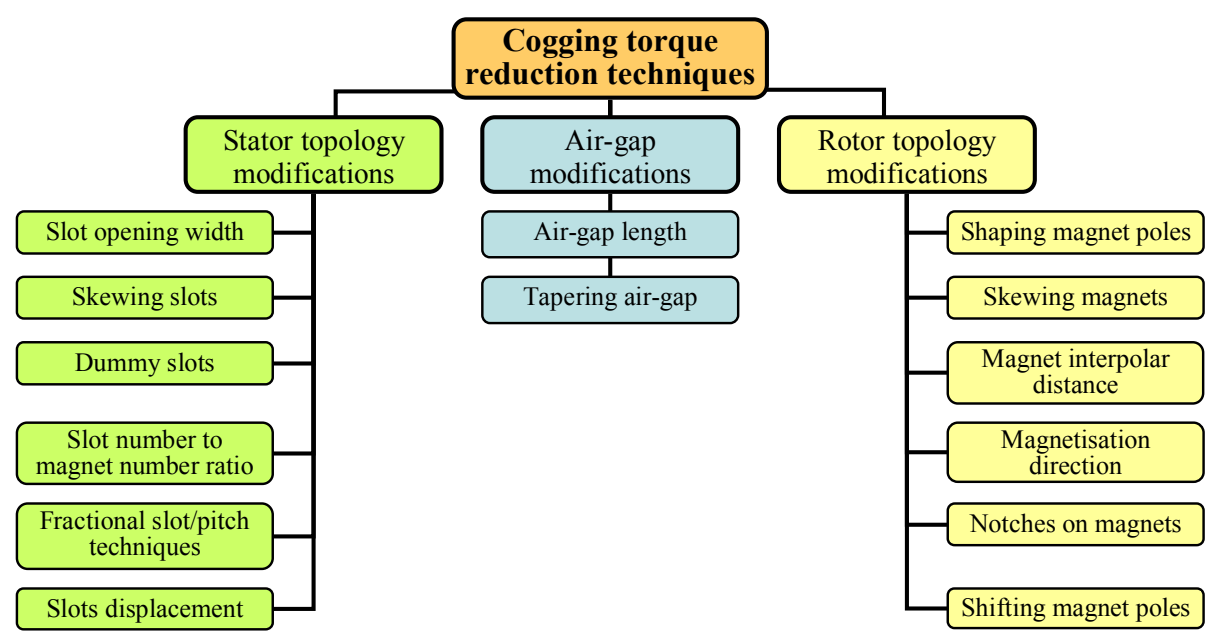


Figure 9. Summary of cogging torque reduction techniques

Only the modifications of the stator topology are considered in the present paper. First a method of cancellation the space harmonics of the cogging torque profile, by stator skewing is analysed. After, the focus is put on the reduction of the stator saliency. A comprehensive investigation and comparison by synthesised 2D Finite Element Analysis (FEA) is presented. The results have revealed that both techniques can significantly contribute to cogging torque reduction, but the latter is more effective than the former. By combining the two techniques, a compound and feasible solution is proposed and evaluated.

\subsection{Skewing the stator slots}

One of the most common techniques to reduce the cogging torque is either by skewing the stator stack or skewing the rotor magnet poles. In SPM machines both are possible. These design solutions can also improve MMF air gap distribution, but the most notable disadvantage is the higher manufacturing cost.

In this study the emphasis is put on the stator topology impact on the cogging torque and therefore the technique of skewing stator slots is analysed. In order to achieve the maximum reduction in the cogging torque the full skew is equal to one slot pitch, and for the analysed motor yields to:

$$
\theta_{s k}=\frac{2 \pi}{N_{s}}=\alpha_{s}=10^{0} \text { mech. }
$$

Skewing is technically a 3D problem, because it is to spatially skew one end of the stator stack a few degrees with respect to the other end of the stack. Hence, for accurate calculation of the cogging torque profile, a 3D FEM should be employed. Due to the time consuming calculations using three-dimensional models, a method for obtaining enough reliable results using multilayer $2 \mathrm{D}$ simulations has been devised. The approach became a routine and is widely used; it is known as "quasi 3D" or "2 1/2D" FEM simulation.

The procedure to obtain the cogging torque curve-angle of a skewed stator stack, from a 2D machine model, is based on the fact that the actual 3D machine with length $L$ and uniform skewing $\theta_{s k}$, can be imagined to correspond to a certain number $N$ of un-skewed (elementary) machines, each having a length of $L / N$. The mutual relative position of two consecutive elementary machines (layers) is displaced for an angle of $\theta_{s k} / N$, where $\theta_{s k}$ is calculated with equation (3). An increase of the number of layers increases the accuracy of calculations. In the analysed case, it is set the number of layers to 10 , giving $1^{0} \mathrm{deg}$. angular increment between two layers. The cogging torque curve, calculated by 2D FEM simulations at a selected start angle, will correspond to the first virtual elementary machine of length $L / 10$. The next layer will have the same cogging torque curve, but displaced for $\theta_{s k} / 10 \mathrm{deg}$. and so forth. The result of the piecewise-skewing of stator slots for the original SPM motor is reported in Figure 10. In Figure 11 is presented the full cycle of the cogging torque profile for the original SPMM with un-skewed slots, in comparison with skewing of $10^{\circ}$ mech.

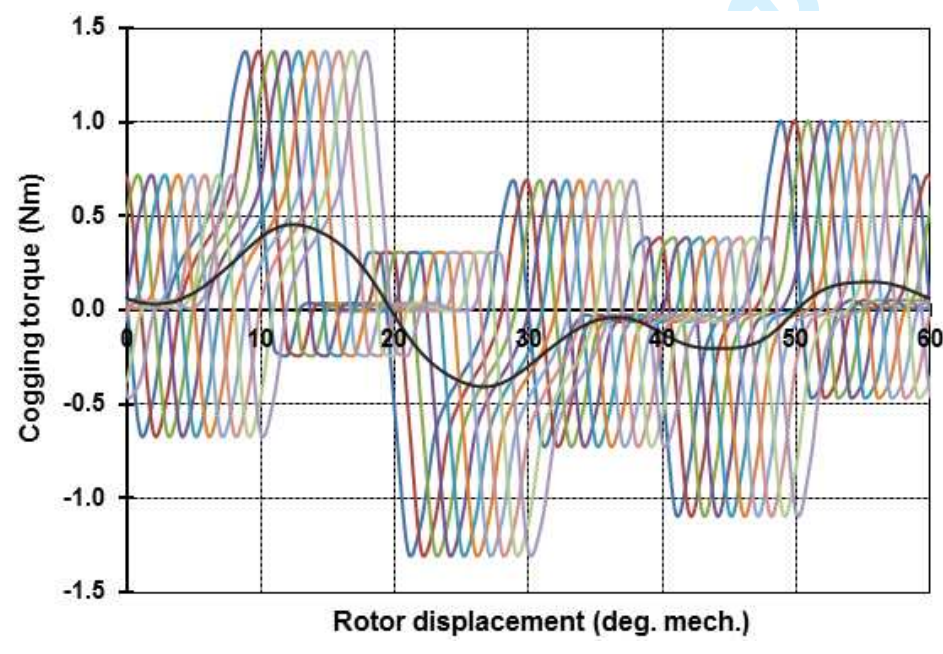

Figure 10. Derivation of cogging torque profile for skewing $10^{0}$ from a 10 -layer model 


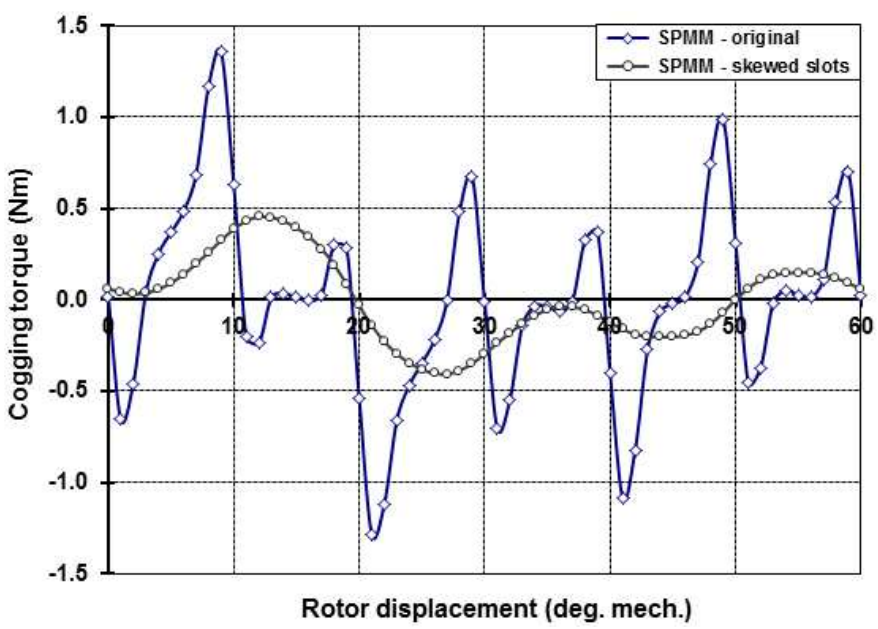

Figure 11. Cogging torque profile of original SPMM with un-skewed and skewed slots

The analysis of characteristics in Figure 11 show significant reduction of the peak cogging torque to $0.454 \mathrm{Nm}$. Compared to the original SPMM it is smaller for almost 3 fold, and even more the value is only $61 \%$ of the that in generic SPMM. At the same time, cogging torque curve is with more favourable profile.

\subsection{Inserting SMC wedges in the stator slots}

Another technique for reducing the cogging torque in SPM motors is to act on the stator saliency. One possibility is to use the additional saliency by introducing the stator dummy slots or rotor notches. The other idea is quite opposite and tends to reduce saliency and to smooth the inner stator surface. Taking into account the constraint of keeping the same stator lamination, it is proposed the stator topology of original SPMM to be upgraded with inserted slot wedges from soft magnetic composite Somaloy ${ }^{\circledR}$.

Soft magnetic composite (SMC) materials offer design advantages when compared to other materials, because of their isotropic nature. The advantages of SMC are used due to the relative ease of producing complex net shaped components by the powder metallurgy production route. A part of the new proposed stator topology is shown in Figure 12.

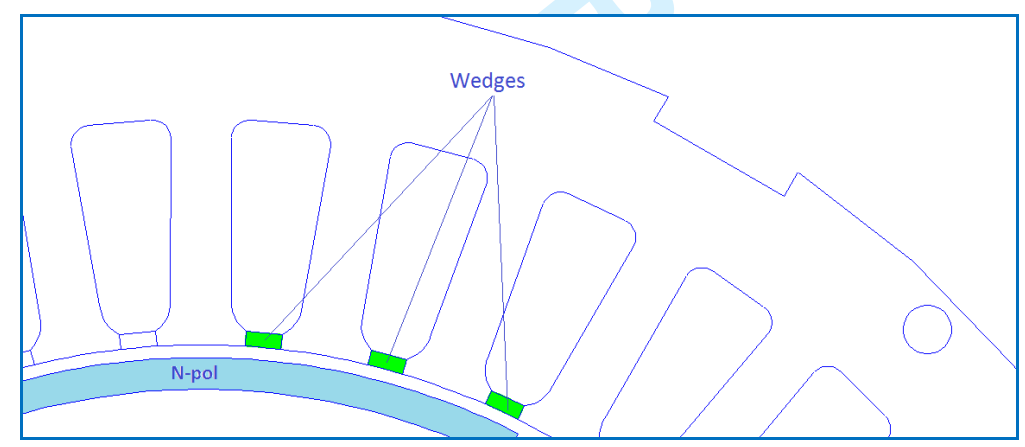

Figure 12. Upgraded SPMM topology: stator slots closed with SMC wedges

The cogging torque-angle curves spanned to a pole pitch of $60^{\circ}$, which is actually a period, for the original SPMM and the topology with closed slots is shown in Figure 13. Evidently, a significant reduction of the peak cogging torque has been achieved; its value is $0.346 \mathrm{Nm}$, which is only $25.5 \%$ of the original SPMM, i.e. reduced for 3.92 times. The profile of the curve follows the similar shape as in the original motor, but the peaks are greatly cut off and with twice less changes of the torque sign. 


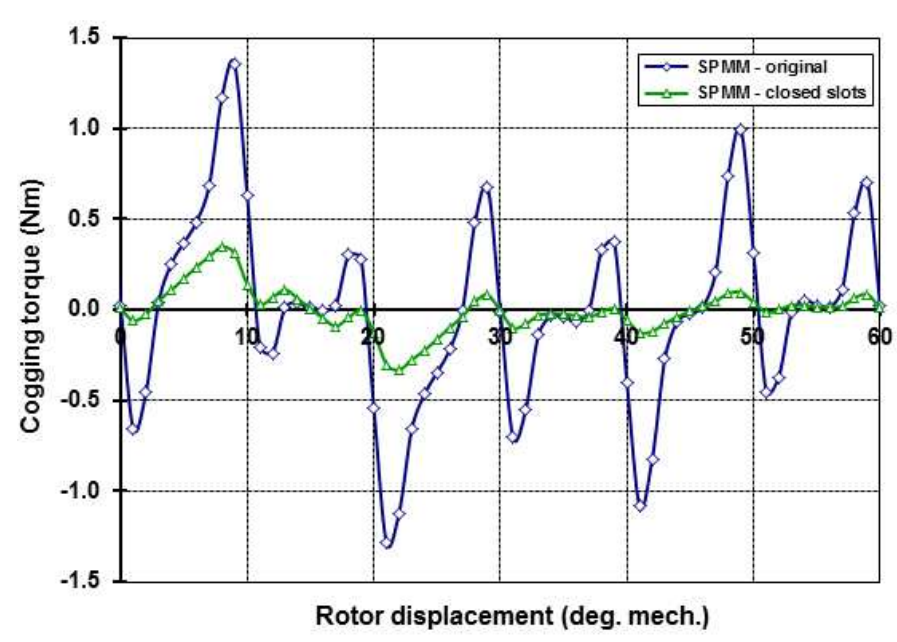

Figure 13. Cogging torque profile over a pole pitch span $60^{\circ}$ mech. of original and SPMM with closed slots

\subsection{Numerical experiment and analysis}

The influence of the slot closures on the performance characteristics of SPM motor is analysed and validated by numerical experiment using 2D FEM. Thorough calculations are carried out and for the both topologies of SPMM the performance characteristics are determined. From the bulk of results, below are presented typical magnetic flux plots and selected characteristics.

First, the analysis is carried out when the magnetic field is energised by PM only. In Figure 14 is presented the open-circuit field distribution, for two rotor positions: (a) initial at $0^{\circ}$; (b) shifted for $30^{\circ}$ mech. $=90^{\circ}$ el.

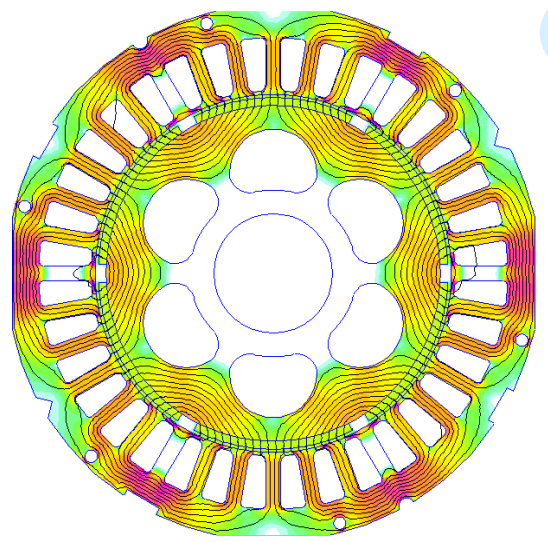

(a) rotor position $0^{0}$
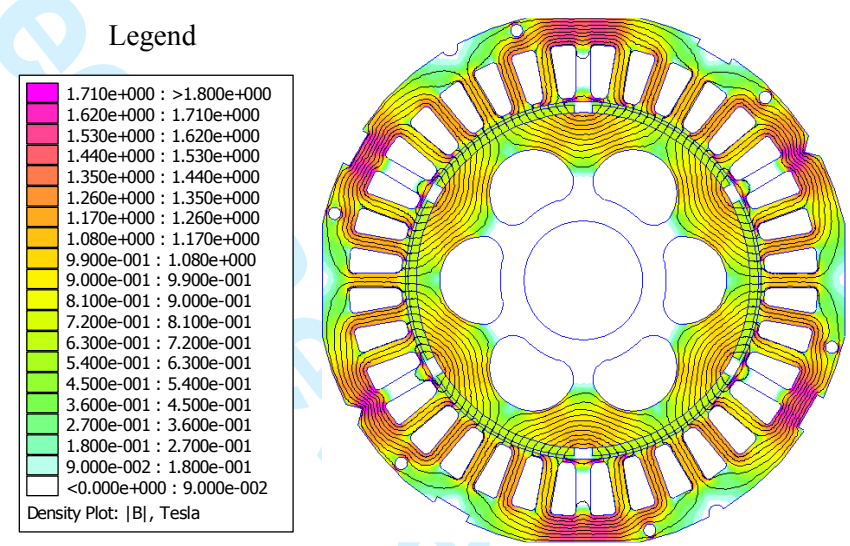

(b) rotor position $30^{\circ}$ mech. $=90^{\circ} \mathrm{el}$.

Figure 14. Open-circuit magnetic field distribution in SPMM with closed stator slots

Comparing Figure 6(b) and Figure 14(a) one can find out lower localised saturation in the stator back iron of the SPMM with closed stator slots than in the original SPMM. On the other hand, a comparison of the plots presented in Figure 14(a) and (b) shows the same saturation pattern, but the regions are simply moved for $30^{\circ}$ in clockwise direction, corresponding to rotor displacement. In Table 2 are presented the values of the magnetic flux density in the points \#1 - \#6 as were depicted in Figure 5; stator closures in the new SPMM compared to the original SPMM reduce localised saturation level in average for $12 \%$, which is a significant gain.

Table 2 Comparison of flux density in selected stator points for SPMM models

\begin{tabular}{|l|c|c|c|c|c|c|}
\hline \multirow{2}{*}{$\begin{array}{c}\text { Magnetic field induced } \\
\text { by PM: rotor position } 0\end{array}$} & \multicolumn{6}{|c|}{$|\mathrm{B}|(\mathrm{T})$ in the point No \# (Fig. 4) } \\
\cline { 2 - 7 } & Flat & \multicolumn{2}{|c|}{ Notch } & Interlock & \multicolumn{2}{c|}{ Rectangular slot } \\
\cline { 2 - 7 } & $\# 1$ & $\# 2$ & $\# 3$ & $\# 4$ & $\# 5$ & $\# 6$ \\
\hline Generic SPMM & 1.38 & 1.40 & 1.39 & 0.95 & 1.4 & 1.4 \\
\hline Original SPMM & 1.59 & 1.73 & 1.77 & 1.46 & 1.66 & 1.74 \\
\hline SPMM with closed slots & 1.48 & 1.52 & 1.58 & 1.35 & 1.56 & 1.61 \\
\hline
\end{tabular}


In the next step, the FEA for both topologies of original SPMM is performed on the rated operation mode. The flux plots are given in Figure 15(a) and (b). The stator back iron in the new proposed SPMM with closure is less saturated. However, it can be noticed slightly higher saturation in the stator teeth and slot SMC closures.

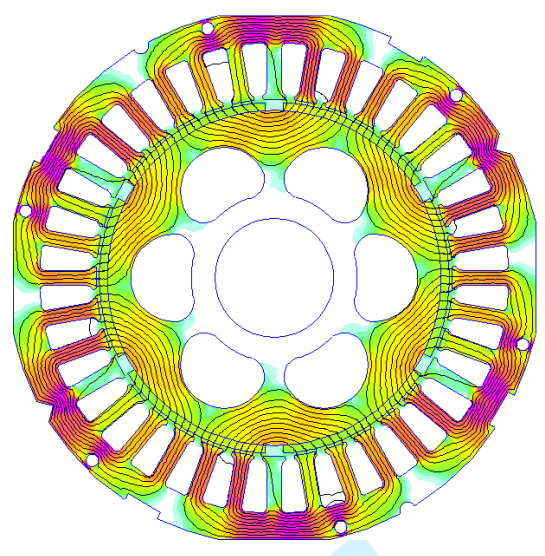

(a) original SPMM

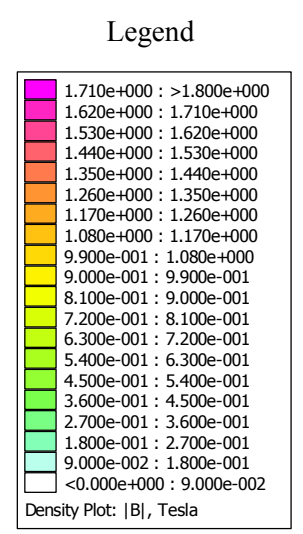

Figure 15. Magnetic field distribution on rated load and rotor position $30^{\circ}$ mech. $=90^{\circ} \mathrm{el}$.

Figure 16 shows the positive effect of the stator slot closures on the flux density distribution along the mid-gap line; for SPM motor with closed slot the curves are smoother. The conclusion is valid for no-load as well as on rated load. Thus, by inserting slot wedges made of soft magnetic composite material, the no-load air-gap magnetic field becomes almost ideally smooth, which is a great advantage.

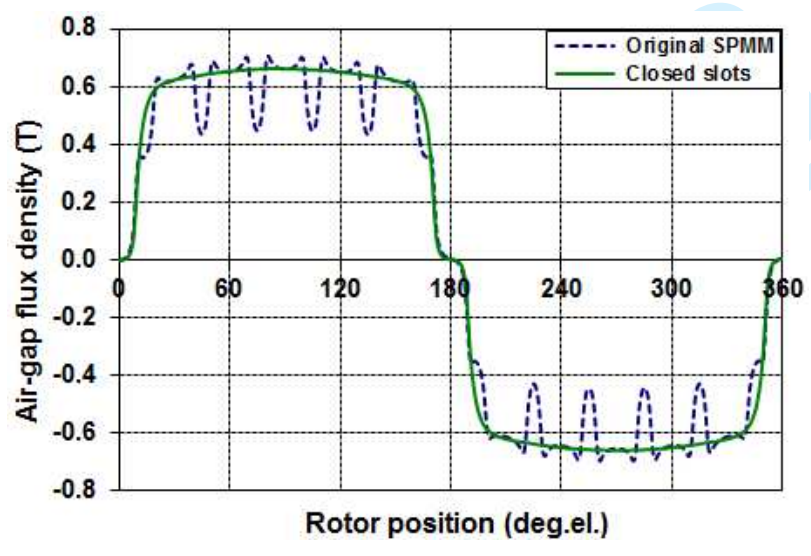

(a) rotor at initial position $0^{0}$ at no-load

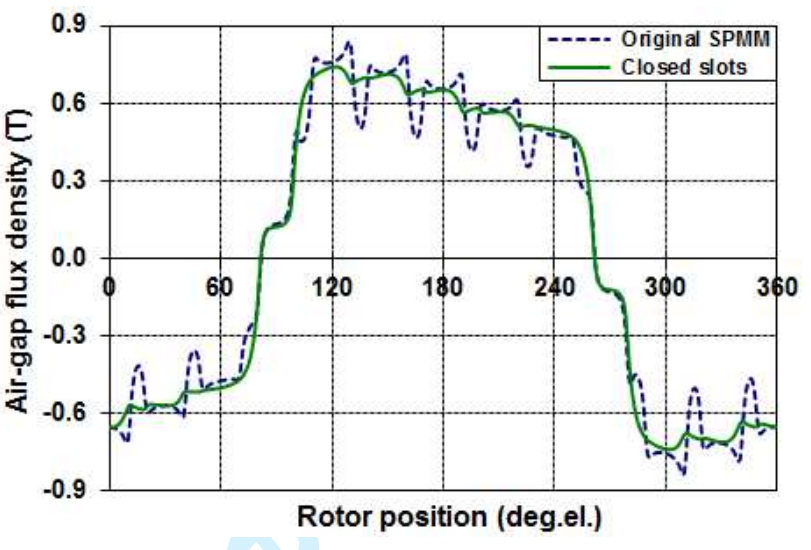

(b) rotor displaced for $30^{\circ}$ in $\mathrm{CW}$ direction at rated load

Figure 16. Full period of the flux density distribution along the mid-gap line

To complete the finite element analysis the curve of the static electromagnetic torque, on rated operation along a pair of poles pitch is derived. The comparative characteristics are presented in Figure 17. The characteristics of the both motor models are with alike shape. However, the less saturated magnetic circuit and lower values of magnetic flux in the SPMM with closed slots yield to lower electromagnetic torque. As result, the maximum torque value (break-down torque) has been decreased from $10.0 \mathrm{Nm}$ to $9.38 \mathrm{Nm}$, i.e. reduction of $6.2 \%$, while in the operating motor range $10^{0}-30^{0}$ the torque values differ from 5-15\%. Actually this fact will cause moving the loading angle of the SPMM for few degrees forward and will not deteriorate the performance of the drive. 


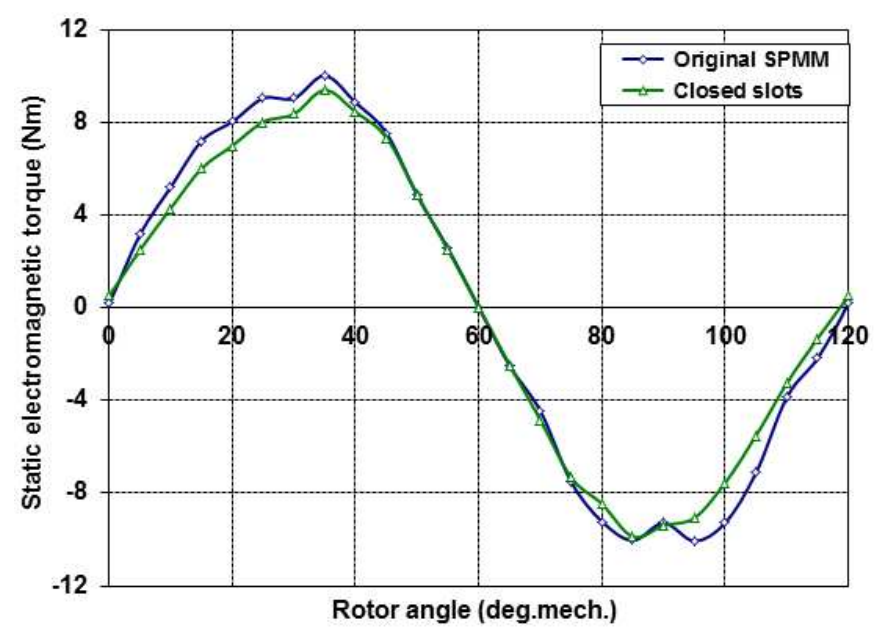

Figure 17. Electromagnetic torque-angle characteristics over a period span $120^{\circ}$ mech.

\section{Compound solution}

To take the advantages of the both techniques for cogging torque reduction, a combination of skewed slots that are closed with SMC material, is proposed and assessed. It has been anticipated this compound solution would combine the advantages of the both techniques, further reducing the peak value of the cogging torque. It is best illustrated in Figure 18(a)-(c), following the cogging torque reduction "history" by implementing separately skewed slots, closed slots and their combination. The cogging torque-angle curve of the compound solution exhibits lower peak value and reduced ripples due to skewing, as well as additional reduction of peak cogging gained due to closed stator slots. Results are summarized in Figure 18(d) and Table 3 for comparison.

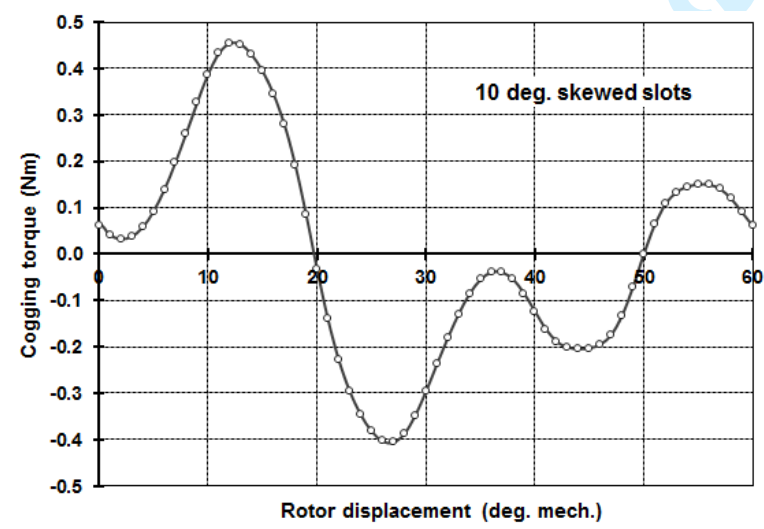

(a) individual contribution of skewed slots for $10^{\circ}$ mech.

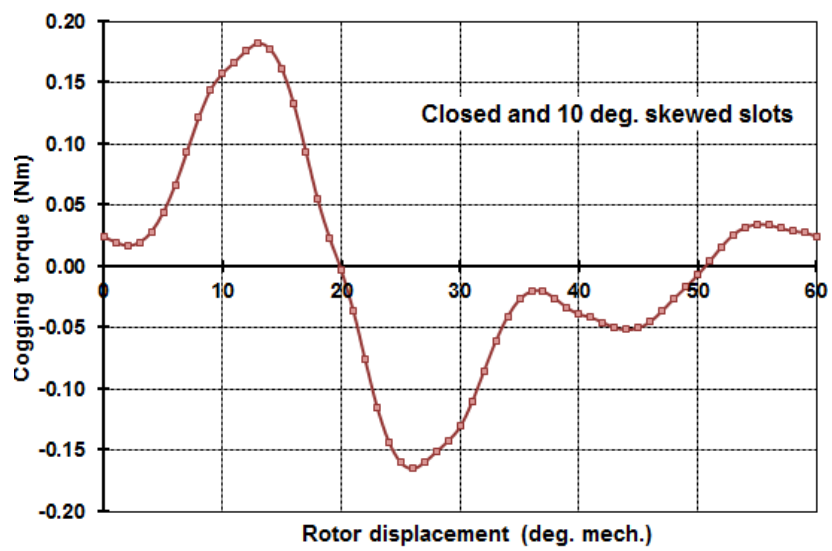

(c) cogging torque of the compound solution

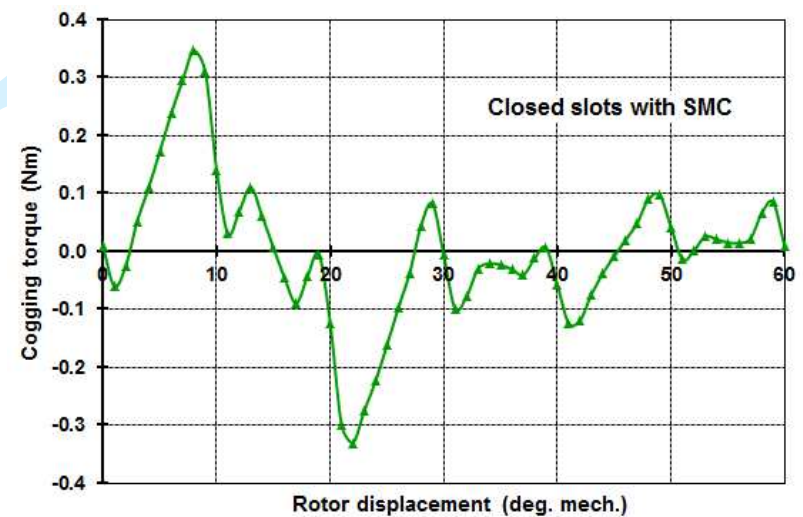

(b) individual contribution of closed slots with SMC

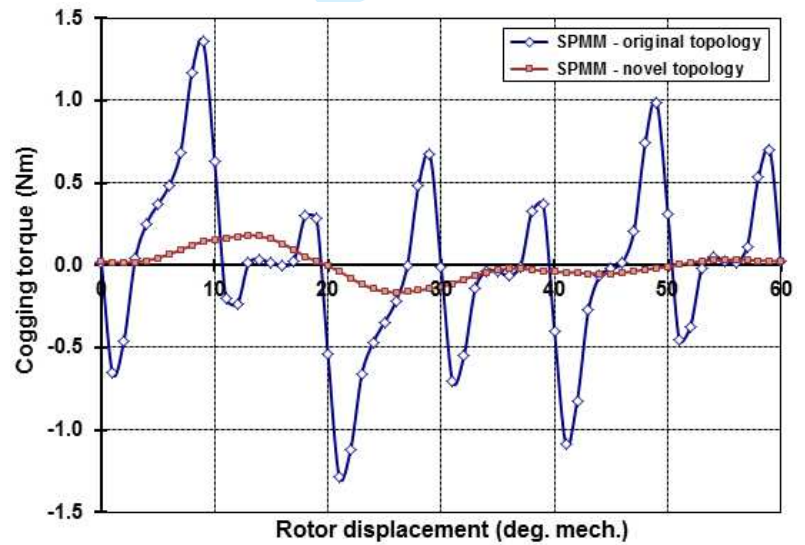

(d) comparison of original and novel topology

Figure 18. History of cogging torque reduction for SPMM 
Table 3 Cogging torque reduction techniques - Summary results

\begin{tabular}{|c|c|c|}
\hline Motor model $\quad$ Result & $\begin{array}{l}\text { Peak cogging } \\
\text { torque }(\mathrm{Nm})\end{array}$ & $\begin{array}{l}\% \text { of original } \\
\text { SPMM }\end{array}$ \\
\hline Generic SPMM & 0.743 & 54.8 \\
\hline Original - unmodified SPMM & 1.356 & 100 \\
\hline Original SPMM - skewed slots $10^{\circ}$ & 0.454 & 33.5 \\
\hline Original SPMM - closed slots with SMC & 0.346 & 25.5 \\
\hline Compound solution - a novel topology & 0.182 & 13.4 \\
\hline
\end{tabular}

\section{Conclusions}

This paper presents stator design considerations of a surface permanent magnet motor (SPMM) for cogging torque reduction and improved performance. The study starts with an analysis of the generic SPMM with smooth stator outer surface. By employing FEM the cogging torque profile and electromagnetic torque characteristics on full load are determined, graphically presented and analysed.

The original design PM machine, with asymmetrically shaped outer stator surface is introduced. The full FEA is accomplished and the impact of stator asymmetry is thoroughly analysed. It is shown that asymmetries cause a significant rise to peak cogging torque and change of the curve periodicity; the peak torque is doubled and the period is changed from $10^{\circ}$ mech. to $60^{\circ}$ mech. In addition, localised higher magnetic field saturations of the stator back iron near cuts and perforations deteriorate drive performance.

In this work, the techniques to reduce cogging torque are considered. Original stator lamination sheet and material properties should not be modified. The research is focussed on the stator topology only. The numerical experiment by using FEA is applied in order to predict the performance characteristics of the SPMM models.

First a technique of skewing stator slots has been implemented. The peak cogging torque gets almost 3 times smaller value, while the number of ripples along a period is halved. The next technique is closing the stator slot openings by inserting wedges produced from soft magnetic composite Somaloy ${ }^{\circledR} 500$. The advantages of this measure are observed in near 4 times decreased peak cogging torque and substantially lower saturation level of the stator back iron. However, the profile of the cogging torque-angle characteristic has kept the shape, and higher saturation level of tooth tips and closures is evident. The curve of the magnetic flux density along the mid-gap line is smoother and the average value is increased. The static electromagnetic torque is slightly decreased which will cause an increase of the loading angle of the permanent magnet motor. The drive performance is not deteriorated.

A compound solution, by combining the two previous techniques, has been proposed and a substantial cogging toque reduction has been achieved. The novel stator topology with skewed and closed slots, results in peak cogging torque of only $0.182 \mathrm{Nm}$, which is reduced for impressive 7.45 times.

The next task will be to analyse the electromagnetic torque characteristic and phase back-EMF waveforms. An analysis of the losses in the slot wedges could also be of interest. This work would serve as a good guide.

\section{References}

Bianchini, C., Immovilli, F., Lorenzani, E., Bellini, A. and Davoli, M. (2012), "Review of Design Solutions for Internal Permanent-Magnet Machines Cogging Torque Reduction", IEEE Transactions on Magnetics, Vol. 48 , No. 10, pp. 26852693.

Chen, N., Ho, S. L. and Fu, W. N. (2010), "Optimization of Permanent Magnet Surface Shapes of Electric Motors for Minimization of Cogging Torque Using FEM, IEEE Transactions on Magnetics, Vol. 46, No.11, pp. 2478-2481.

Choi, J.S., Izui, K., Nishiwaki, S. and Kawamoto, A. (2011), "A Topology Optimization of the Stator for Minimizing Cogging Torque of Interior Permanent Magnet (IPM) Motors", IEEE Transactions on Magnetics, Vol. 47, No. 10, pp. 3024-3027.

Fei, W. and Zhu, Z. Q. (2013), "Comparison of Cogging Torque Reduction in Permanent Magnet Brushless Machines by Conventional and Herringbone Skewing Techniques", IEEE Transactions on energy Conversion, Vol. 28, No. 3, pp. 664674.

Gasparin, L. and Fiser, R. (2013), "Sensitivity of Cogging Torque to Permanent Magnet Imperfections in Mass-produced PM Synchronous Motors", Journal Przeglad Elektrotechniczny (Electrical Review), Vol. 89, No. 2b, pp. 80-83.

Gholamian, S. A. and Rashidaee, S. (2012), "Cogging Torque Reduction in Surface Permanent Magnet (SPM) Motors Using Taguchi Experiment Design and Finite Element Method", I.J. Intelligent Systems and Applications, Vol. 4, No. 11, pp. 33-39.

Gonzales, D. A., Tapia, H. A. and Battancourt, A. L. (2007), "Design Consideration to Reduce Cogging Torque in Axial Flux Permanent-Magnet Machines", IEEE Transactions on Magnetics, Vol. 43, No. 8, pp. 3435-3440.

Guemes, J. A., Iraolagoitia, A. M., Del Hoyo, J. I. and Fernandez, P. (2011), "Torque Analysis in Permanent-Magnet Synchronous Motors: A Comparative Study", IEEE Transactions on energy Conversion, Vol. 26, No. 1, pp. 55-63.

Hanselman, Duane C., "Brushless permanent-magnet motor design", (book), New York: McGraw-Hill Inc., USA, 1994, pp. $103-123$ 
Ionel, D. M., Popescu, M., Mc Gilp, M. I., Miller, T. J. E. and Dellinger, S. J. (2005), "Assessment of Torque Components in Brushless Permanent-Magnet Machines Through Numerical Analysis of the Electromagnetic Field", IEEE Transactions on Industry Applications, Vol. 41, No. 5, pp. 1149-1158.

Kim, D-H., Park I-H., Lee, J-H. and Kim C-E. (2003), "Optimal Shape Design of Iron Core to Reduce Cogging Torque of IPM Motor", IEEE Transactions on Magnetics, Vol. 39, No. 3, pp. 1456-1459.

Kudrjavtsev, O. and Kilk, A. (2014) "Cogging torque reduction methods", Proceedings of the Electric Power Quality and Supply Reliability Conference - PQ, Rakvere, Estonia, pp. 251-254.

Kwack, J., Min, S. and Hong, J-P. (2010) "Optimal Stator Design of Interior Permanent Magnet Motor to Reduce Torque Ripple Using the Level Set Method", IEEE Transactions on Magnetics, Vol. 46, No. 6, pp.2108-2111.

Levin, N., Orlova, S., Pugachov, V., Ose-Zala, B. and Jakobsons, E. (2013), "Methods to Reduce the Cogging Torque in Permanent Magnet Synchronous Machines", Jornal Elektronika IR Elektrotechnika, ISSN 1392-1215, Vol. 19, No. 1, pp. 23-26.

Petkovska, L. and Cvetkovski, G. (2011), "Assessment of Torques for a Permanent Magnet Brushless DC Motor Using FEA", Journal Przeglad Elektrotechniczny (Electrical Review), Vol. 87, No. 12b, pp. 132-136.

Petkovska, L. and Cvetkovski, G. (2012), "Influence of the Stator Yoke Design on Torque Characteristics for Permanent Magnet Synchronous Motor", Book of Digests of XXII Polish Symposium on Applied Electromagnetism in modern Technologies and Informatics - PTZE, pp. 167-169, Sandomierz, Poland.

Petkovska, L., Lefley, P., Cvetkovski, G. and Ahmed, S. (2013), "Shaping the Stator Poles of BLDCPM Motor for Cogging Torque Reduction", Journal Przeglad Elektrotechniczny (Electrical Review), Vol. 89, No. 2b, pp. 42-45.

Stumberger, B., Stumberger, G., Hadziselimovic, M., Marcic, T., Virtic, P., Trlep, M. and Gorican, V. (2008), "Design and Finite-Element Analysis of Interior Permanent Magnet Synchronous Motor with Flux Barriers", IEEE Transactions on Magnetics, Vol. 44, No. 11, pp. 4389-4392.

Zhu, Z. Q., Chen, J. T. and Howe, D. (2008), "Influence of Stator Asymmetry on Cogging Torque of Permanent Magnet Brushless Machines", IEEE Transactions on Magnetics, Vol. 44, No. 11, pp. 3851-3854. 